\title{
Effect of Seeding Time on Fatty Acid Composition, Oil Contents and Seeds Yield in Flax
}

\author{
Hong Jib Choi ${ }^{1}$, Shin Young Park ${ }^{2}$ and Sang Kuk Kim ${ }^{1}$ * \\ ${ }^{1}$ Division of Crop Science, Gyeongsangbuk-do Agricultural Research \& Extension Services, Daegu 702-708, Korea \\ ${ }^{2}$ Department of Clinical Pathology, Jeju Halla University, Jeju 690-708, Korea
}

\begin{abstract}
Influences of different seeding dates on growth, seed yield, fatty acid composition and oil content were investigated in flax plants for two years. The results indicated that plant height in early seeding date was higher than that of delayed seeding dates during first season. Furthermore, seeding date also significantly affected the ripened seed rate and the rate increased with the delay in seeding date in first season. Seed yield in the first crop season was significantly higher than the second crop season. Palmitic acid showed variation in different seeding dates. Contrarily, stearic acid was stable and did not changed by different seeding dates. Linolenic acid was found in highest amount in all seeding dates consecutively in two cropping years. Highest oil content was recovered from the seeds of flax sown at 29 Apr. and May 9 in first and second cropping year respectively.
\end{abstract}

Key words - Flax, Linum usitatissimum L., Temperature, Oil, Fatty acid

\section{Introduction}

It is generally thought that the seeds of oilseed plant grown under warmer climate condition contain less highly unsaturated fat. In soybeans, linolenic acid is negatively correlated with high temperature (Collins and Howell, 1957). For flax, the most important environmental factor is temperature (Canvin, 1965), with other environmental factors may also be involved (Dybing, 1964). The mechanisms by which environmental effects are produced have not been clearly defined. The technique of observing the changes in fatty acid levels which occur in developing seeds during the period from fertilization to maturity was used to assess the effects of temperature, photoperiod, and light intensity on fatty acid biosynthesis in flax.

Flax (Linum usitatissimum L.) is an annual crop belongs to the family Linaceae (Simmonda 1976). Worldwide flax seeds are used for oil extraction and its skin of stem for fiber purpose. The defatted seeds are fed to animals as a protein supplement (Lennerts, 1983). Flaxseed meal contains 35 to $40 \%$ protein, and together with cottonseed and sunflower supplies about $23 \%$ of the world's oilcake and meal (Hatje, 1989). In our country, flax had been extensively cultivated as a fiber crop early 1960s. However, flax production has declined with the import of nylon and cotton since the 1970s. Recently, flax has been cultivated for its oil rich seeds. Flax seed oil has been used as a drying agent for paints, varnishes, lacquer, and printing ink. Recently there has been some interest in flax seeds as a health food because of its high amount of polyunsaturated fatty acids in the seed oil. It is thought that flax is an alternative cash crop, especially in some areas of Gyeongsangbuk-do Province. Though flax has been cultivated on the clay soils in the northern area of Andong, however, flax has also been adapted and is successfully grown in other areas of the Gyeongsangbuk-do Province. Flax production is always dependent on sowing time rather than planting density. In flax the tendency for highest seed yield is associated with early planting. This study was aimed at investigating the effects of seeding dates on early growth, seed yield, change in fatty acid composition, and oil content of flax seed for two cropping years.

${ }^{*}$ Corresponding author. E-mail : sk2@korea.kr 


\section{Materials and Methods}

\section{Plant material and general procedures}

Seeds of flax (Linum usitatissimum L. cv. Hwanam) which was developed by a pure line selection at the Institute for Bioresources Research, Gyeongsangbuk-do Provincial Agricultural Research \& Extension Services, Andong, Korea, were used in this study.

A sowing date trial of four planting dates (April 9, April 19, April 29, and May 9,) was laid out to investigate the appropriate sowing time of flax in 2009 and 2010 crop seasons. Flax seeds were hill-seeded with a spacing of plant to plant $30 \mathrm{~cm}$ and row to row $10 \mathrm{~cm}$ distance. respectively. Prior to planting, fertilizers Nitrogen, Phosphorus, and Potassium were applied at the rate of 100,25 , and $90 \mathrm{~kg} \mathrm{ha}^{-1}$, incorporating as a basal and top dressing $(7: 3, \mathrm{w} / \mathrm{w})$ to the soil. The experiments with three replications were laid out in randomized complete block design.

\section{Oil extraction and analysis of fatty acids}

The total oil contents of flax seeds were determined by solvent extraction using $n$-hexane in a Soxhlet apparatus following the standard AOAC procedure (1984). Each sample was ground to a powder and dried under vacuum to a constant weight. To each specimen $0.1 \mathrm{mg}$ of an internal standard (nonadecanoic acid) was added. The powder was extracted with chloroform/methanol $(2: 1, \mathrm{v} / \mathrm{v})$ as described elsewhere (Chamberlin et al., 1993) and the solid, nonlipid material was removed by filtration. The total weight of the extracted lipid was determined gravimetrically after solvent removal in a stream of nitrogen. The samples were then redissolved in dry chloroform/methanol (19:1, v/v) and clarified by centrifugation. A $0.1-\mathrm{ml}$ aliquot was withdrawn for transmethylation using $0.3 \mathrm{ml}$ of $14 \% \mathrm{BF} 3$ in methanol in a 2-ml Teflonlined screw-cap vial which was heated in a boiling water bath for $15 \mathrm{~min}$. After cooling and addition of $0.3 \mathrm{ml}$ of water, the transmethylated fatty acids were extracted into hexane. A calibration mixture of fatty acid standards was processed in parallel. Aliquots of the hexane phase were analyzed by GC/MS. A Hewlett-Packard Gas Chromatograph (5890 Series II) with the Mass Selective Detector 5972A in scan mode was used to separate and quantify fatty acids. Aliquots ( 1 to $2 \mathrm{ml}$ ) of the hexane extract were injected in splitless mode onto a DB-225 column (30 m1 $0.25 \mathrm{~mm}$ I.D., $0.24 \mathrm{~mm}$ ). The injector temperature was $2507 \mathrm{C}$, detector at $2807 \mathrm{C}$, oven at $707 \mathrm{C}$ for $1 \mathrm{~min}$, then 70 $1807 \mathrm{C}$ at $207 \mathrm{C}$ per min, $180-2207 \mathrm{C}$ at $37 \mathrm{C}$ per min, $2207 \mathrm{C}$ for $15 \mathrm{~min}$. The carrier gas was helium and the flow rate was $32 \mathrm{~cm} / \mathrm{s}$. Electronic pressure control in the constant flow mode was used. The internal standard nonadecanoic acid was used for quantification of fatty acids. Fatty acid calibration standards and nonadecanoic acid were procured from Alltech, Deerfield, IL. Solvents were purchased from EM Science, Gibbstown, NJ.

\section{Statistical analysis}

The standard deviation was calculated using Sigma plot 2001 software (Jandel Scientific, San Rafael, CA, USA).

\section{Results and Discussion}

\section{Growth characteristics and seeds yield}

Growth characteristics and seed yields of flax plants grown under different seeding dates for two cropping years (2009 and 2010) are given in Table 1. Overall, the flowering time in all seeding dates in the first crop season (2009) was delayed as compared to that of second crop season (2010). However, the possible reason for delay in flowering in first crop season is the prevailing low weather conditions as indicated in Fig.1. It is also concluded that the ambient mean temperature in first crop season (2009) is low as compared to second crop season (2010). Results of sowing dates effect on early flowering are quite in harmony with the findings of (Turhan et al., 2011) that has worked on sowing management trails and suggested that early sowing dates results in earlier flower than late sowing. In late sowing dates, flax plants get a short duration to flowering.

Plant height of flax was also significantly different for various seed sowing dates Table I. The plant height in early sowing date was recorded higher than those of late sowing dates in the first season. The flax plants from second season were longer than the flax plants from first season. Our results are in conformity with those obtained by Sankari (2000), who found that humidity and temperature differences caused a 
wide variation between flaxseed cultivars for mean plant height

Number of capsule per plants was significantly increased by delayed sowing dates, 29 Apr. and 9 May in both cropping years. The highest capsule numbers was observed and may be due to a temperature effect on pollination, ovary survival in delayed sowing dates which is in agreement with Mirshekari et al.(2012).

Seeding date affected significantly the ripened seed rate. The late sowing dates yielded the more ripened seed and the rate of ripened seeds increased as the sowing dates was delayed in first crop season (2009). However, it was not affected by seeding date in second cropping year. In early sowing dates the plant growth may be inferior stunted due to low temperature in the beginning which decrease the uptake of essential nutrients and thus impaired the plant physiological function including flowering and ripened seed yield. This may also be attributed to early flowering in late sowing plants and more time for ripening the seeds.

Thousand seed weight is an important yield contributing parameter. Different sowing dates significantly influenced thousand seed weight in first crop year (2009). In the first crop year (2009) thousand seed weight in flax at three seeding dates (19 Apr., 29 Apr., and 9 May) was significantly heavier (Table 1) as compared to the early seeding date (9 Apr.). However, the differences for thousand seed weight among the sowing dates were found non-significant in second crop year (2010).

Seed yield is the basic parameter in all oilseed crops, and has been the key factor in all agriculture experiments. A

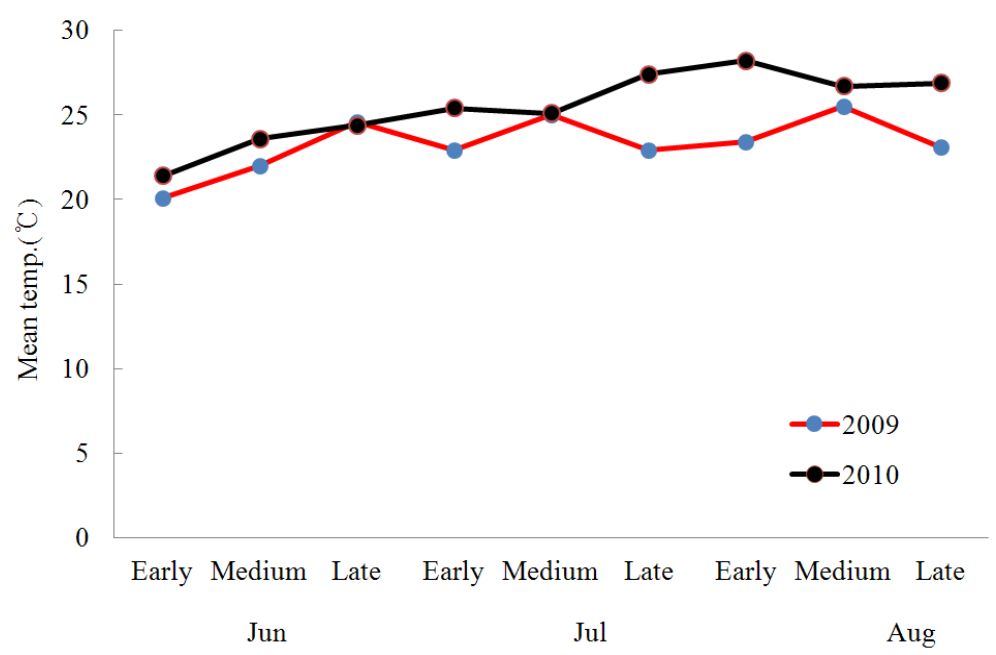

Fig. 1. Changes in ambient mean temperature during seed development of flax for two cropping years, 2009-2010.

Table 1. Effect of different seeding dates on agronomic traits and yield and yield components of flax in two cropping years

\begin{tabular}{|c|c|c|c|c|c|c|c|}
\hline Cropping year & $\begin{array}{l}\text { Seeding } \\
\text { time }\end{array}$ & $\begin{array}{l}\text { Flowering } \\
\text { time }\end{array}$ & $\begin{array}{l}\text { Plant } \\
\text { height } \\
(\mathrm{cm})\end{array}$ & $\begin{array}{c}\text { No. of capsule } \\
\text { per plant }\end{array}$ & $\begin{array}{c}\text { Ripened } \\
\text { seed rate } \\
(\%)\end{array}$ & $\begin{array}{c}1,000 \text {-seed } \\
\text { weight } \\
(\mathrm{g})\end{array}$ & $\begin{array}{c}\text { Seed } \\
\text { yield } \\
(\mathrm{kg} / 10 \mathrm{a})\end{array}$ \\
\hline \multirow{4}{*}{2009} & Apr 9 & Jun. 7 & $85.6 \mathrm{a}$ & $17.1 \mathrm{c}$ & $88.6 \mathrm{~b}$ & $5.91 \mathrm{c}$ & $161 \mathrm{c}$ \\
\hline & Apr 19 & Jun.18 & $81.4 \mathrm{~b}$ & $18.9 \mathrm{~b}$ & $93.7 \mathrm{a}$ & $6.30 \mathrm{~b}$ & $179 b$ \\
\hline & Apr 29 & Jun.27 & $79.3 \mathrm{bc}$ & $20.2 \mathrm{ab}$ & $93.5 \mathrm{a}$ & $6.31 \mathrm{~b}$ & $185 \mathrm{ab}$ \\
\hline & May 9 & Jul. 5 & $76.5 \mathrm{c}$ & $21.5 \mathrm{a}$ & $94.1 \mathrm{a}$ & $6.42 \mathrm{a}$ & $196 \mathrm{a}$ \\
\hline \multirow{4}{*}{2010} & Apr 9 & Jun. 4 & $87.2 \mathrm{a}$ & $16.8 \mathrm{c}$ & $86.7 \mathrm{a}$ & $5.76 a$ & $155 b$ \\
\hline & Apr 19 & Jun.13 & $87.6 \mathrm{a}$ & $18.5 b$ & $86.6 \mathrm{a}$ & $5.82 \mathrm{a}$ & $164 a$ \\
\hline & Apr 29 & Jun.26 & $84.3 \mathrm{~b}$ & $21.1 \mathrm{a}$ & $85.2 \mathrm{a}$ & $5.73 a$ & $168 \mathrm{a}$ \\
\hline & May 9 & Jul. 1 & $84.0 \mathrm{~b}$ & $20.7 \mathrm{ab}$ & $86.1 \mathrm{a}$ & $5.76 \mathrm{a}$ & $176 \mathrm{a}$ \\
\hline
\end{tabular}

The same letters in each column are not significantly different at $5 \%$ level by DMRT. 
significant variation was found in seed yield (Table 1) of flax due to different sowing dates and crop year. Seed yield in the first crop season (2009) was significantly higher than that of the second crop season (2010). Highest seed yield were recorded in the late sowing date (May 9) followed by Apr 29 and Apr 19 in first crop season (2009). For second crop year (2010) the difference in seed yield among the first sowing date (Apr 9) and the last three sowing dates (Apr 19, Apr 29, May 9) was also significant. However, the seed yield in second crop year (2010) in last three sowing dates was at par with each other. The highest seed yield in delayed sowing is due to highest number of capsule per plant, ripened seed rate and heavier thousand seed weight and these results are in conformity with Casaa et al.(1999).

\section{Changes of fatty acid composition and oil content}

The content change in saturated fatty acids compositions i.e. palmitic and stearic acid, as affected by different seeding dates for two cropping years are presented in Figure 2.1. The content change in palmitic acid was up and down regulated in different seeding dates, whereas stearic acid remained unchanged in different seeding dates. The amount of palmitic acid ranged from 4.0 to $5.5 \mathrm{mg}$ per g DW and stearic acid ranged from 4.0 to $4.55 \mathrm{mg}$ per g DW, respectively. Palmitic acid increased in the first season and stearic acid increased only in second season in all seeding dates. This can be attributed to higher mean temperature in the second season during seed development (Fig. 1). Consequently, the content changes in two saturated fatty acids depends on ambient temperature during seed ripening and our results indicated the increase in stearic acid and decrease in palmitic acid content during higher temperature.

Three unsaturated fatty acid contents were also influenced not by rather than seeding dates but ambient temperature during seed development in two cropping years (Fig. 2-2). Oleic acid was slightly increased with increasing temperature
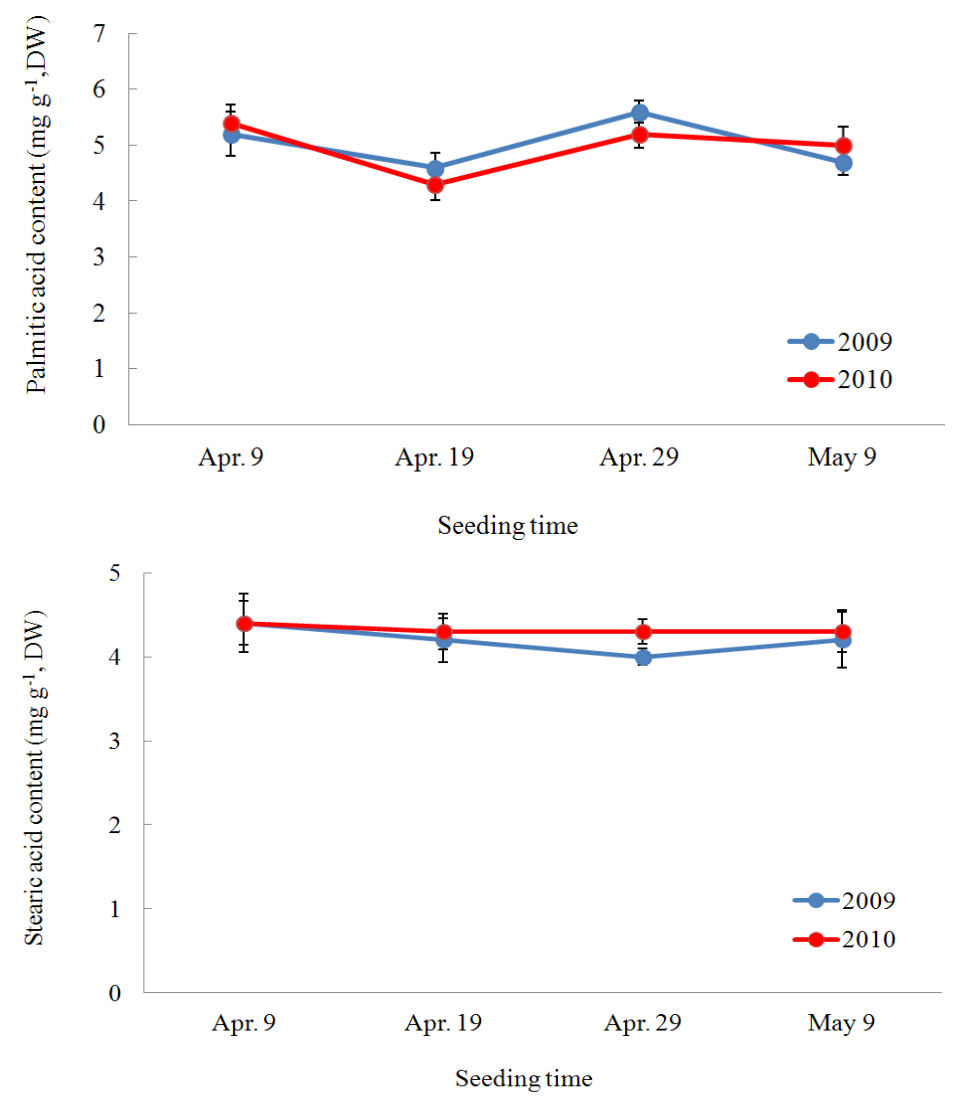

Fig. 2-1. Effect of different seeding dates on variation in contents of saturated fatty acid (palmitic and stearic acid) of flax for two cropping years, 2009-2010. Vertical bars represent the mean \pm SE $(n=4)$. If not shown, error bars are smaller than the symbol size. 
during seed ripening in second cropping year, whereas it was relatively decreased in first cropping year with lower temperature than that of second cropping year. Linoleic acid was always lower than that of oleic acid in all seeding dates at two cropping years. However, linoleic acid was always increased in first cropping year compared to the second cropping year. Interestingly, higher temperature during seed ripening significantly affected increased linoleic acid in all seeding dates in second cropping year (Fig. 2-1; Fig. 2-2). Among these unsaturated fatty acids, linolenic acid had a greatest content for all seeding dates in two cropping years. Its content was also highest at 29 Apr. in first cropping year.
It was reported that fatty acid composition was strongly affected by temperature in soybean and linoleic and linolenic acid decreased markedly whereas oleic acid increased as the temperature increased (Wolf et al., 1982).

Oil content increased markedly (37\%) as the temperature increased during seed ripening in first cropping year (Fig. 3). In the first cropping year, highest oil content was observed in flax seed sown on 29 Apr. (43.5\% per $100 \mathrm{~g} \mathrm{DW}$ ) and was followed by 9 Apr., 19 Apr., respectively. Moreover, in second cropping year, highest oil contents were recorded in the late seeding date, 9 May. In our results, oil contents may depends on temperature which was relatively low during flax
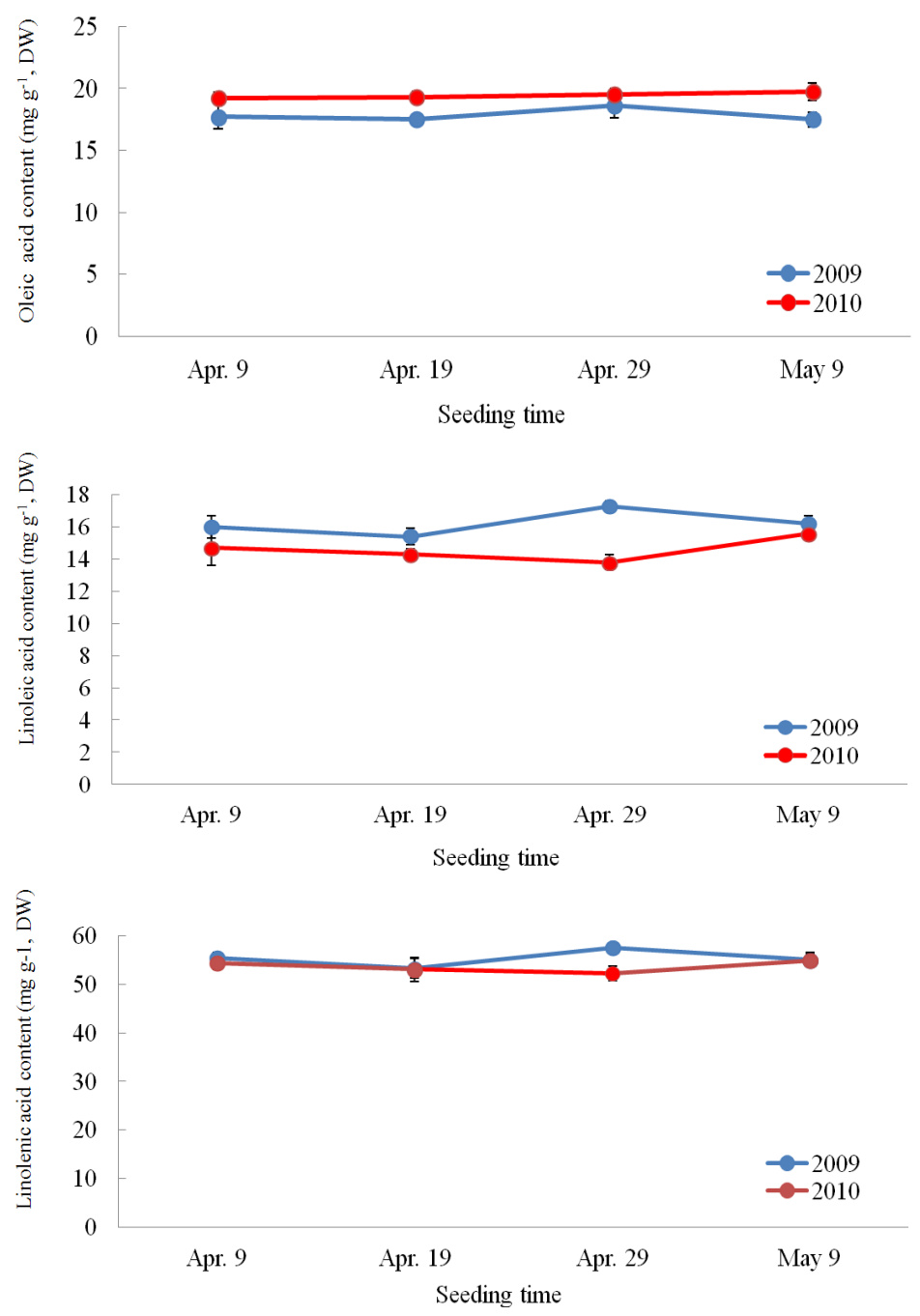

Fig. 2-2. Effect of different seeding dates on variations of contents in unsaturated fatty acid (oleic acid, linoleic acid and linolenic acid) of flax for two cropping years, 2009-2010. Vertical bars represent the mean $\pm S E(n=4)$. If not shown, error bars are smaller than the symbol size. 


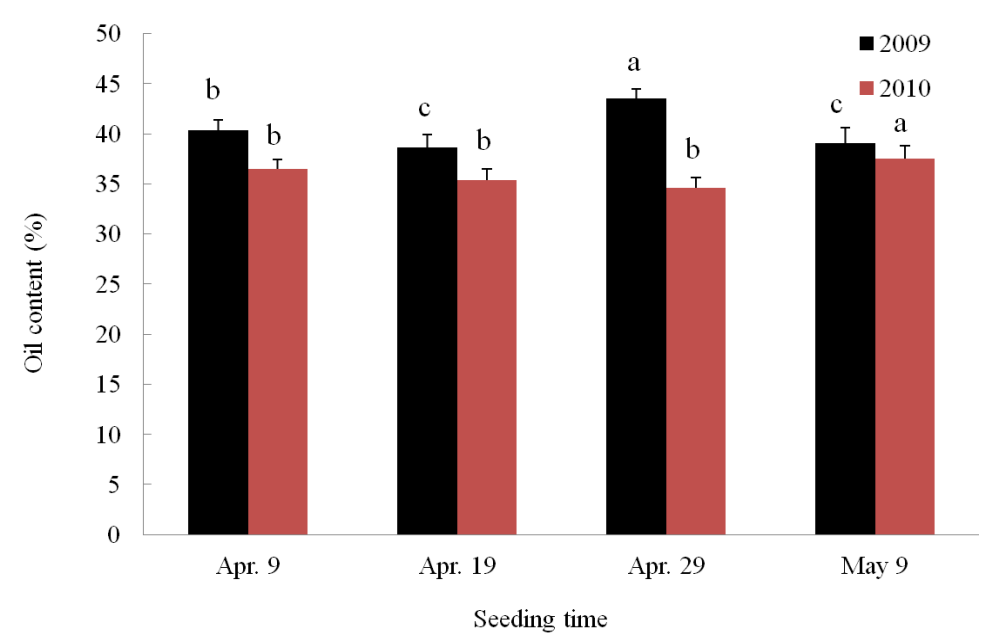

Fig. 3. Effect of seeding time on oil contents of flax for two years, $2009-2010$. Vertical bars represent the mean $\pm \mathrm{SE}(\mathrm{n}=4)$.

seed ripening ranged from 20 to $23^{\circ} \mathrm{C}$. Similar results were reported and the researchers found that oil contents significantly increased in oat grain as the temperature lowers during the seed ripening compared to effect of low temperature in early growth stage (Saastamoinena et al, 1990; Thompson et al.. 1973).

\section{Literature Cited}

AOAC. 1984. Methods of analysis of the association of official analytical chemists. 14th edn., In Horowitz, W. (ed.), Association of Official Analytical Chemists, Washington, DC., USA. pp. 12-15.

Canvin, D.T. 1965. The effect of temperature on the oil content and fatty acid composition of the oils the oil s from several oil seed crops. Can. J. Bot. 43:63-69.

Casaa, R., G. Russellb, B. Lo Cascioa and F. Rossinia. 1999. Environmental effects on linseed (Linum usitatissimum L.) yield and growth of flax at different stand densities. Euro. J. Agron. 11:267-278.

Chamberlain, J., G. Nelson and K. Milton. 1993. Fatty acid profiles of major food sources of howler monkeys (Aloutta palliata) in the neotropics. Experientia 49:820-823.

Collins, F.I. and R.W. Howell. 1957. Factors affecting linolenic and linoleic acid content of soybean oil. Agron. J. 49:593-597.

Dybing, C.D. 1964. Influence of nitrogen level on flax growth and oil production in varied environments. Crop Sci. 4:491-494.
Gross, A.T.H. 1963. Effect of data of sowing on yield, plant height, flowering and maturity of rape and turnip rape. Agron. J. 56:76-78.

Hatje, G. 1989. World importance of oil crops and their products. In G. Robbellen, R.K. Downey and A. Ashri. (eds.), Oil Crops of the World: their breeding and utilization, McGraw-Hill Pub. Co., New York, USA. pp. 1-21.

Hocking, P.J. and M. Stapper. 2001. Effect of sowing time and nitrogen fertilizer on canola and wheat, and nitrogen fertilizer on Indian mustard. I. dry matter production, grain yield, and yield components. Aust. J. Agric. Res. 52:623-634.

Lennerts, L. 1983. Oelschrote, oelkuchen, pflanzliche oele und fette, herkunft, gewinnung, verwendung. Bonn. Verlag Alfred Strothe, Hannover, Germany. pp. 29-31.

Moore, M.K. and S. Guy. 1997. Agronomic response of winter rapeseed to rate and data of seeding. Agron. J. 89:521-529.

Mirshekari, M., R. Amiri, H.I. Nezhad, S.A.S. Noori and O.R. Zandvakili. 2012. Effects of planting date and water deficit on quantitative and qualitative traits of flax seed. AmericanEurasian J. Agric. \& Environ. Sci. 12:901-913.

Saastamoinena, M., K. Jorma, N. Seppo and H. Ulla. 1990. Effect of temperature on oil content and fatty acid composition of oat grains. Acta Agr. Scand. 40:349-356.

Sankari, H.S. 2000. Linseed (Linum usitatissimum L.) cultivars and breeding lines as stem biomass producers. J. Crop. Sci., 184:225-131.

Simmonda, N.W. 1976. Evolution of Crop Plants. Longman Inc., New York., USA. p. 15.

Thompson, D.L., M.D. Jellum and C.T. Young. 1973. Effect of controlled temperature environments on oil content and on 
fatty acid composition of corn oil. J. Am. Oil Chem. Soc. 50:540-542.

Turhan, H., M.K. Gu., G.O. Egesel and F. Kahriman. 2011. Effect of sowing time on grain yield, oil content, and fatty acids in rapeseed (Brassica napus subsp. oleifera). Turk J. Agric. For. 35:225-234.

Uzun, B., U. Zengin, S. Furat and O. Akdesir. 2009. Sowing date effects on growth, flowering, seed yield and oil content of canola cultivars. Asian J. Chem. 21:1957-1965.

Wolf, R.B., J. F. Cavins, R.Kleiman and L.T. Black. 1982. Effect of temperature on soybean seed constituents: oil, protein, moisture, fatty acids, amino acids and sugars. J. Am. Oil Chem. Soc. 59:230-232.

(Received 9 October 2012 ; Revised 20 November 2012 ; Accepted 27 December 2012) 